\title{
PERCEPÇÃO DO ESTUDANTE DE EDUCAÇÃO TÉCNICA A DISTÂNCIA DE NÍVEL MÉDIO SOBRE A REALIZAÇÃO DAS TAREFAS AVALIADAS NO AMBIENTE VIRTUAL
}

\author{
(STUDENT PERCEPTION OF MID-LEVEL DISTANCE TECHNICAL EDUCATION REGARDING \\ EVALUATED TASKS IN THE VIRTUAL ENVIRONMENT)
}

\author{
Alexandre Costa Quintana \\ Vera Lucia Pinheiro Fernandes \\ Universidade Federal do Rio Grande (FURG), Brasil
}

\section{RESUMO}

O advento da tecnologia da informação e comunicação permite que o processo de ensinoaprendizagem não fique restrito a sala de aula; ele rompe estas fronteiras permitindo que o estudante construa seu conhecimento no ambiente de trabalho, doméstico ou onde ele estiver e no horário que melhor lhe convir. Assim, a educação a distância ganha espaço neste contexto, e junto surge um questão relacionada: a como avaliar este estudante? No ambiente virtual, normalmente a avaliação é feita uma parte virtualmente, por meio de atividades propostas pelo professor e outra presencial. Sendo assim, a atividade avaliada torna-se de grande importância para o estudante, pois além de somar a sua nota final, faz com que o mesmo sinta-se parte integrante deste processo ensino-aprendizagem ao participar das atividades, chats e fóruns. Neste sentido, este trabalho teve por objetivo verificar a percepção do estudante da educação técnica a distância de nível médio sobre a realização de suas tarefas avaliadas no Ambiente virtual de aprendizagem. Este trabalho foi executado por meio de uma pesquisa descritiva, com abordagem e análise de resultados quantitativos e qualitativos. Os resultados mostram que os estudantes consideram as tarefas avaliadas no ambiente virtual de aprendizagem essenciais no seu processo ensino-aprendizagem, além de destacarem que as mesmas são necessárias para um bom rendimento na sua avaliação final. No entanto, há alguns pontos que precisam de atenção como: material didático objetivo, maior comprometimento de coordenadores/ professores/tutores nas respostas as suas dúvidas, além da questão do tempo para postagem das tarefas. Acredita-se que com uma maior atenção a estas solicitações, as tarefas avaliadas terão cada vez mais relevância e importância neste processo ensino-aprendizagem.

Palavras-chave: EAD, tarefas avaliadas, ensino.

\section{ABSTRACT}

The advent of information and communication technology enables the process of teaching and learning to not be limited to the classroom; it breaks these boundaries allowing students 
to develop their knowledge at work, home or any other placer, and at a time that is most convenient. Thus, distance education is gaining ground in this context. As a result, another question arises: how do we assess the student? In a virtual environment, students are normally evaluated virtually, for example, by means of activities provided by the professor. On the other hand, students can be assessed in other ways. Distance education, as a relatively new type of education, is undergoing a process where many questions arise. One of the main questions is how to evaluate the student. Usually this evaluation is done virtually, e.g. through activities proposed by the teacher, and other class activities. Therefore, the activity that is being evaluated becomes of great importance to the student. Besides, adding to the final grade makes him/ her feel part of the learning process: In addition, the student can participate in the activities, chats and forums. In this sense, this paper aims to verify the students' perception of midlevel distance technical education - and their performance during the evaluation of tasks in a virtual learning environment. This work was performed by means of a descriptive approach to analyzing quantitative and qualitative results. The results show that students recognize the tasks evaluated as being extremely important in their learning process. However, there are some points that need extra attention such as courseware objectives, greater involvement of coordinators/teachers/tutors in the answers to student questions, plus the question of time for posting tasks. It is believed that by placing greater attention to these demands, the assessed tasks will be increasingly relevant and important in the teaching-learning process.

Keywords: Distance education, tasks evaluated, education.

A educação a distância, modalidade de ensino aparentemente nova no Brasil, já era legalmente prevista desde a edição da Lei de Diretrizes e Bases (LDB) de 1996, pois em seu artigo 80, a Lei $n^{0}$ 9.394, de 20 de dezembro de 1996, já cita ser de responsabilidade do poder público incentivar o desenvolvimento e a veiculação de programas de ensino a distância, em todos os níveis e modalidades de ensino. Esta modalidade de ensino se diferencia das demais pelo fato do estudante e professor estarem em ambientes físicos diferentes, e na maioria das vezes, a quilômetros de distância um do outro, porém eles encontram-se ligados por um ambiente virtual de aprendizagem, mediante a utilização de meios e Tecnologias da Informação e Comunicação (TICs), por meio do qual o professor insere o conteúdo referente ao curso que o estudante está cursando.

De acordo com o Decreto $\mathrm{n}^{0}$ 5.622, de 19 de dezembro de 2005, do Ministério da Educação, o ensino a distância poderá ser ofertada em vários níveis e modalidades educacionais, desde a educação básica até a superior, sendo que este estudo focou a Educação Profissional Técnica de Nível Médio. Quanto à carga horária do curso na modalidade a distância, o decreto afirma que não deve haver diferenciação de carga horária do curso realizado na modalidade a distância ou presencial.

A modalidade de educação a distância surge no século XX como uma alternativa, diante da enorme demanda por educação, principalmente da classe trabalhadora, 
que necessitava ampliar seus estudos, mas não tinha tempo e muitas vezes nem recurso financeiro para frequentar as instituições de ensino.

O advento da tecnologia da informação e comunicação permite que o processo de ensino-aprendizagem não fique restrito a sala de aula; ele rompe estas fronteiras permitindo que o estudante construa seu conhecimento no ambiente de trabalho, doméstico ou onde ele estiver e no horário que melhor lhe convir.

Para Aretio (1995), a Educação a Distância (EAD) distingue-se da modalidade de ensino presencial por ser um sistema tecnológico de comunicação bidirecional, que substitui a interação pessoal na sala de aula entre professor e estudante, como meio preferencial de ensino, pela ação sistemática e conjunta de diversos recursos didáticos, com o apoio de uma organização e tutoria que propiciam uma aprendizagem independente e flexível.

Entre os muitos questionamentos da EAD, está o de como se dá o processo avaliativo nesta modalidade, já que existe um distanciamento físico professor/ estudante. Neste estudo procura-se responder a seguinte questão: Qual a percepção do estudante da Educação Técnica a distância de Nível Médio sobre a realização de suas tarefas avaliadas no ambiente virtual?

A avaliação da EAD tem sido tema de muitos estudos que objetivam analisar a mais adequada forma de avaliação dos estudantes em EAD, sendo que a legislação permite que parte desta avaliação ocorra mediante atividades programadas no ambiente virtual, mas obriga a realização de avaliações de forma presencial e exige que as notas destas avaliações presenciais prevaleçam sobre as notas das atividades realizadas no ambiente virtual de ensino- aprendizagem.

Desta forma, este trabalho tem como objetivo analisar a percepção do estudante da Educação Técnica a Distância de Nível Médio sobre a realização de suas tarefas avaliadas no Ambiente Virtual. Para responder a este objetivo foi desenvolvido um questionário com perguntas abertas e fechadas com estudantes da Educação Técnica a Distância de Nível Médio, que procurou verificar quais fatores que interferem na decisão de resolução das tarefas virtuais; quais momentos de estudos ocorrem até a finalização das tarefas avaliadas e como o estudante percebe a tarefa em relação à utilidade no processo de avaliação e aprendizagem.

O estudo justifica-se pela necessidade de investigação e reflexão sobre a importância da realização das tarefas (atividades), como parte integrante e essencial do processo de avaliação em EAD, principalmente, considerando que a legislação 
permite que parte da nota final do estudante, seja composta por atividades avaliativas realizadas no ambiente virtual.

Para Libâneo (1991), a avaliação é uma tarefa didática essencial para o trabalho docente. Por apresentar uma grande complexidade de fatores, ela não pode ser resumida a simples realização de provas e atribuição de notas. A mensuração apenas fornece dados quantitativos que devem ser apreciados qualitativamente.

\section{FUNDAMENTAÇÃO TEÓRICA}

Nesta seção são abordados a educação a distância, avaliação e aprendizagem e as tecnologias da informação e comunicação -TICs.

\section{A Educação a Distância}

No cenário nacional, a Educação a Distância se desenvolve conforme os avanços nos recursos tecnológicos e de comunicação. A primeira iniciativa neste sentido deu-se no século XIX, com a oferta de cursos profissionalizantes, por meio de correspondência, como exemplo pode-se citar o Instituto Monitor fundado em 1939. Já no século XX surgiram os cursos que se utilizavam de recursos radiofônicos e televisivos para ministrarem aulas, neste seguimento têm-se os cursos de Teleducação/Telecursos (Maia \& Mattar, 2007). Os autores apresentam a trajetória da educação a distância numa perspectiva histórica daquilo que denominam de "gerações da EAD". Classificam-nas em três gerações: a primeira geração seriam os cursos por correspondência, a segunda constituir-se-ia nas novas mídias e as universidades abertas, e por fim, a terceira geração seria o advento da EAD on-line.

Com a terceira geração em EAD surgem os Ambientes Virtuais de Aprendizagem (AVA) e essa modalidade de educação se transforma, ultrapassa barreiras e ganha espaço no cenário nacional e internacional.

No Brasil têm-se muitos programas que oferecem cursos na modalidade de educação a distância. Entre estes programas podem-se elencar dois que fazem parte dos programas em EAD do Ministério da Educação e que já estão há algum tempo disponibilizando esta modalidade de educação. A Universidade Aberta do Brasil (UAB) foi criada pelo Ministério da Educação no ano de 2005, com vistas à expansão da educação superior, no âmbito do Plano de Desenvolvimento da Educação (PDE) (CAPES, 2012). Segundo dados do CAPES (2012), o sistema UAB, no ano de 2009, contava com 720 polos e 88 Instituições entre Universidades Federais, Universidades Estaduais e Institutos Federais de Educação, Ciência e Tecnologia (IFETs). 
Outro programa de EAD que pertence ao Ministério da Educação é a Rede e-Tec Brasil lançado em 2007. O sistema Rede e-Tec Brasil visa à oferta de educação profissional e tecnológica a distância e tem o propósito de ampliar e democratizar o acesso a cursos técnicos de nível médio, públicos e gratuitos, em regime de colaboração entre União, Estados, Distrito Federal e Municípios. Os cursos são ministrados por instituições públicas e o MEC é responsável pela assistência financeira na elaboração dos cursos. Aos Estados, Distrito Federal e Municípios cabe providenciar estrutura, equipamentos, recursos humanos, manutenção das atividades e demais itens necessários para a instituição dos cursos (MEC, 2012).

Segundo dados do portal do MEC em 2008, seu primeiro ano efetivo de atuação, o programa Rede e-Tec Brasil contou com 193 polos regionais e atendeu a 23 mil estudantes. Em 2010, o número de polos chegou a 259, localizados em 19 Estados, e cerca de 29 mil estudantes foram atendidos. Em 2011, encontravam-se matriculados na Rede e-Tec aproximadamente 80 mil estudantes. O MEC prevê que a oferta de vagas continue em crescimento pelos próximos anos. Até 2014, a previsão é de atender pelo menos 263 mil estudantes pela Rede e-Tec Brasil (MEC, 2012).

Enquanto um sistema atende a educação superior o outro atende a educação profissional de nível médio.

De acordo com Keegan (1991), os elementos centrais para caracterização de um sistema de Educação a Distância são:

- a separação do professor e estudante no espaço e/ou tempo;

- o controle do aprendizado realizado mais intensamente pelo estudante do que pelo professor; e

- a comunicação entre estudantes e professores que é mediada por documentos impressos ou alguma forma de tecnologia.

Barbosa et al. (2007) afirmam que o professor em EAD tem o papel de mediador das relações entre o estudante e o conhecimento a ser adquirido. A interação professor-estudante e a interação entre os grupos de estudantes são vistas de maneira imprescindível para que o conhecimento aconteça, sendo que o professor sai do papel de transmissor de um conhecimento pronto, para o papel de mediador no processo de construção dos saberes por parte dos estudantes. 
Moura, Azevedo e Mehlecke (2011), também enfatizam a importância de diversos aspectos relacionados à colaboração, interação e socialização no processo de construção do conhecimento, e o professor é um mediador, aquele que mostra o caminho para que os estudantes busquem de forma interativa o conhecimento.

Sobre a educação a distância Moran (2011) esclarece que a Educação a distância não é um espaço em que o estudante se serve de algo pronto. Na verdade, tratase de uma prática que permite um equilíbrio entre as necessidades e habilidades individuais e as do grupo, onde é possível avançar rapidamente, trocar experiências, esclarecer dúvidas e inferir resultados.

Neste contexto, esta forma de aprender e ensinar é algo enriquecedor, pois não coloca o estudante como mero espectador, ele se torna o centro deste processo, o que evidência nesta modalidade de educação, uma função que vai além de educar, ela é capaz de transformar pessoas, pois as ensina a pensar, a ser críticos e acima de tudo aprender a aprender, do seu jeito e no seu tempo.

\section{Avaliação e Aprendizagem}

A avaliação entendida como uma ação pedagógica necessária para a qualidade do processo ensino-aprendizagem deve cumprir, basicamente, três funções didáticopedagógicas: diagnóstica, formativa e somática (Piletti, 1987; Libâneo, 1991; Zabala, 1999; Haydt, 2002).

A função diagnóstica da avaliação refere-se à identificação do nível inicial de conhecimento dos discentes naquela área, bem como a verificação das características e particularidades individuais e grupais dos estudantes, ou seja, é aquela realizada no início do curso ou unidade de ensino, a fim de constatar se os discentes possuem conhecimentos, habilidades e comportamentos necessários para as novas aprendizagens. É utilizada também para estimar possíveis problemas de aprendizagem e suas causas (Haydt, 2002).

A função formativa é aplicada durante o processo de ensino-aprendizagem funcionando como um feedback imediato acerca do rendimento do estudante e das fragilidades da didática aplicada, contribuindo para a realização de possíveis ajustes necessários ao planejamento do ensino, tendo em vista o alcance dos objetivos previamente traçados (Zabala, 1999).

A função somativa, por sua vez, visa classificar os estudantes de acordo com seus níveis de aproveitamento no processo de ensino-aprendizagem. É realizada ao final 
de um curso ou período letivo, segundo critérios previamente estabelecidos, e visa à promoção do estudante de um nível para outro (Haydt, 2002).

Para Luckesi (2005) avaliar tem o significado de diagnosticar e intervir, o que representa praticar a investigação sobre o que está acontecendo, tendo a intenção de proceder a intervenções adequadas, no sentido de melhorar os resultados. Se o professor conseguir avaliar o estudante de forma a diagnosticar suas falhas poderá intervir a tempo para que este estudante construa seu conhecimento e alcance os resultados esperados.

Em função das especificidades da EAD é fundamental que a avaliação ocorra de maneira diferenciada. Silva (2006) afirma que a avaliação da aprendizagem na sala de aula on line exige rupturas com o modelo de avaliação tradicional presencial. O professor precisa buscar novas posturas, novas estratégias de engajamento no contexto, mesmo da docência e da aprendizagem e, assim, redimensionar suas práticas de avaliar a aprendizagem e sua própria atuação.

Em razão destas especificidades, Alonso (2005) adverte que antes de se pensar em avaliar o estudante, na educação a distância tem-se também de avaliar o sistema, e um fator relevante para avaliação de um sistema de educação a distância é o índice de evasão, que é considerado "indicador de análise de efetividade dessa modalidade". De acordo com o modelo e características de um sistema de EAD, o estudante pode desenvolver o sentimento de fazer parte da instituição ou de completo isolamento em relação a esta, o que pode interferir muito em seu processo de aprendizagem. $\mathrm{O}$ estudante tem que sentir que faz parte da instituição, o ambiente de aprendizagem tem que ser agradável, para que ele, estudante, seja parte atuante deste processo de ensino; senão houver esta interação, também não haverá aprendizagem.

Em EAD uma avaliação formativa pode se dar por meio, de um fórum de discussão on line sobre um assunto que o professor vai abordar, sendo uma forma de avaliação colaborativa e dialógica. Barilli (2006) aponta que a avaliação colaborativa estimula o poder de negociação, pois este ambiente de aprendizagem possibilita a formação subambientes dentro dos quais os diferentes grupos que constituem a comunidade de aprendizagem interagem objetivando um produto comum. Habilidades ligadas à pesquisa, síntese e redação são trabalhadas, nesta proposta de avaliação.

Bassani e Behar (2006) apresentam um modelo de avaliação que leva em conta tanto aspectos quantitativos quanto aspectos qualitativos e prevê também a análise do processo de construção do conhecimento do estudante pelo professor. As autoras consideram que um sistema avaliativo completo, incorporado em AVA, 
deve considerar: a avaliação de testes on line, em que o estudante responderá a uma série de questões corrigidas automaticamente pelo sistema; a avaliação da produção individual, que envolve a realização de pesquisas e a elaboração de textos pelo estudante e, finalmente, a análise das interações dos estudantes realizadas por meio das ferramentas de comunicação do ambiente.

No caso da EAD, as ferramentas de comunicação presentes no AVA possibilitam o registro das interações entre os estudantes e entre estudantes e docentes, o que permite que a avaliação supere o caráter estritamente mecânico e quantitativo (Otsuka \& Rocha, 2002; Barbosa, 2005). O professor com acesso ao ambiente virtual consegue ver quantas vezes o estudante acessou a plataforma da disciplina, qual material ele revisou, quanto tempo ele levou revisando o material, quanto tempo ele levou para fazer a tarefa de avaliação, e isso é um dos fatores que contribui para o professor verificar as dificuldades deste estudante e também serve de base para a avaliação futura, pois todo o histórico deste estudante fica registrado no ambiente virtual, contribuindo para que os professores possam traçar um perfil deste estudante.

Quanto ao uso do sistema para proceder à avaliação através das contribuições dos estudantes, Fuks, Gerosa e Lucena (2001), observam ser uma tarefa bastante árdua para o professor, visto que este tem de estar sempre atento ao acesso dos estudantes ao sistema, além de ter a função de acompanhar, avaliar e motivar as interações de seus aprendizes.

Segundo Luckesi (2005), a avaliação contribui para uma apreciação acerca da eficácia da didática e dos recursos pedagógicos empregados e favorece a tomada de decisões durante o processo de ensino-aprendizagem, visando melhorar a qualidade do conhecimento que se está construindo.

A avaliação, seja na educação a distância ou presencial, não deve nunca ser usada como elemento punitivo, mas sim como algo que visa diagnosticar, rever práticas e valorizar a educação.

\section{Tecnologias da Informação e Comunicação - TICs}

Com o advento das tecnologias da informação e comunicação o mundo se transforma, abrem-se novas expectativas em todas as áreas, econômica, política, social e educacional. O termo TIC refere-se à conjugação da tecnologia computacional ou informática com a tecnologia das telecomunicações e tem na Internet e mais particularmente na World Wide Web (Rede de Alcance Mundial) WWW ou simplesmente Web a sua mais forte expressão. A Web funciona como 
uma espécie de repositório mundial de informações. Segundo Miranda (2007), a utilização dessas tecnologias para fins educativos, promovem relacionamentos e troca de conhecimento, fazendo com que a Web deixe de ser apenas um repositório de informações.

Estas transmissões em rede podem ser feitas via rádio, satélite ou linha telefônica, isto faz com que atualmente, possa se ter acesso à rede em todo e qualquer lugar e a qualquer hora. Um avanço no Brasil, com um território imenso, com enormes desigualdades sociais e que necessita uma educação mais democratizada.

Atualmente, o estudante não precisa ter um computador e acesso a rede para fazer um curso a distância, pois os próprios sistemas educacionais, neste caso podem citar a UAB e o sistema Rede e-Tec possuem polos (são locais onde o estudante tem assistência, como tutoria presencial para esclarecimentos e acesso a rede) distribuídos por várias regiões, nas zonas urbana e rural.

Hoje é possível ministrar uma aula por meio de um recurso chamado videoconferência que é um sistema interativo de comunicação em áudio e vídeo que permite que a interatividade aconteça em tempo real, ampliando o conceito de tempo e espaço em sala de aula estendendo-se o evento presencial para grandes distâncias. Este recurso permite uma troca de experiência sem igual, pois pessoas a quilômetros de distância com culturas diversas podem trocar informação e aprender em tempo real.

Fuks, Gerosa e Lucena (2001), corroboram com este pensamento ao destacar que, no grupo ocorre a complementação de capacidades, de conhecimentos e de esforços individuais, e a interação entre pessoas com diferentes entendimentos, pontos de vista alternativos e habilidades complementares.

Barreto (1996) define o termo informação como sendo estruturas significantes com a competência de gerar conhecimento no indivíduo, em seu grupo, ou a sociedade. Trata-se de um conceito amplo e significativo que se aplica aos participantes de um ambiente virtual de aprendizagem.

Babin e Kouloumdjian (1989), em suas pesquisas com os jovens ante a realidade da comunicação advinda com os avanços das tecnologias, confirmam a hipótese de que a invasão das mídias e o emprego das tecnologias na vida cotidiana modelam progressivamente outro comportamento intelectual e afetivo. São outras maneiras de compreender, de perceber, de sentir e de aprender, em que a afetividade, as relações, a imaginação e os valores não podem deixar de ser considerados. São alternativas de 
aprendizagem que os auxiliam a interagir, a escolher e a participar nas estruturas sociais e educativas.

Para Maciel (2002) é preciso ter clareza de que o ambiente virtual de aprendizagem não assegura o desenvolvimento da inteligência coletiva ou de relações sociais cooperativas, apenas fornece a infraestrutura e a arquitetura telemática para o desenvolvimento de uma comunicação multidirecional, por meio da qual é possível estabelecer fluxos de comunicação entre todos e fazer circular os saberes apropriados e construídos por sujeitos singulares que interagem no ambiente. Para que a inteligência coletiva possa ser construída é preciso, ainda, que os vários sujeitos conectados ao ambiente virtual tenham disponibilidade, tanto subjetiva como objetiva, para tecer relações de troca e que estejam envolvidos na busca coletiva do conhecimento, para transformar o mundo.

A evolução tecnológica não se restringe aos novos usos de equipamentos e/ou produtos, mas aos comportamentos dos indivíduos que interferem/repercutem nas sociedades, intermediados, ou não, pelos equipamentos. Portanto, entende-se como tecnologias os produtos das relações estabelecidas entre sujeitos com as ferramentas tecnológicas que têm como resultado a produção e disseminação de informações e conhecimentos. Mas de nada adianta assegurar acesso à informação em rede e educação em massa, sem se ter um plano de educação voltado para cidadania (Kenski, 2003).

Quando se desenvolve um ambiente de aprendizagem, faz-se uma opção teórico-metodológica que tem implícito uma abordagem de desenvolvimento e de aprendizagem humana, uma visão de homem, de ciência, de trabalho, de mundo.

Consideradas a abrangência e a especificidade da construção de um ambiente de aprendizagem e as tarefas pedagógicas implicadas em um projeto desta natureza, fica muito clara a necessidade do suporte de diversos paradigmas, de um elenco de princípios, de um conjunto de categorias procedentes de diversas bases do conhecimento.

Porfírio e Mello (2007) descrevem as TICs como instrumentos que facilitam o processo de formação do estudante. Entre as ferramentas de TICs que favorecem a EAD, destaca-se o Moodle, que é um Sistema Open Source de Gerenciamento de Cursos Course Management System (CMS), também conhecido como Learning Management System (LMS) ou um AVA. O Moodle é muito usado por educadores de todo o mundo como uma ferramenta para criar sites de $w e b$ dinâmicos e criativos para seus estudantes. Para funcionar, ele precisa ser instalado em um servidor $w e b$, 
em seu próprio computador ou numa empresa de hospedagem. O Moodle é gratuito para download e o seu registro é voluntário, portanto segundo dado do próprio site é impossível determinar o número de usuários deste sistema (Moodle, 2012).

O Moodle através da Web é uma ferramenta que propicia os educadores gerenciar e promover a aprendizagem, pois permite usabilidade em grande escala para centenas de estudantes, além de dispor de módulo de atividades onde é possível inserir os mais diversos tipos de atividades.

Quintana e Quintana (2012) afirmam ser o Moodle um sistema de gestão de ensino e aprendizagem com muitas vantagens, pois permite maior interação entre professores, tutores e estudantes. É preciso que se tenha claro que os recursos tecnológicos e de comunicação nada significam em si, nada fazem por si só, eles precisam e devem estar a serviço de um plano pedagógico claro e muito bem planejado, pois só assim vão cumprir sua missão em EAD que é encurtar distâncias, democratizar a educação e acima de tudo, humanizar as relações, pois robôs são os computadores, os que estão à sua frente são seres humanos.

\section{METODOLOGIA}

Em termos, metodológicos, este trabalho pode ser classificado, quanto aos objetivos, como descritivo. Gil (2010) enfatiza que a pesquisa descritiva tem como objetivo primordial a descrição das características de determinadas população ou fenômeno, utilizando-se de técnicas padronizadas de coleta de dados, tais como o questionário e a observação sistemática.

Quanto à abordagem do problema a pesquisa classifica-se como quantitativa e qualitativa, pois utilizou-se um questionário que após ter suas respostas tabuladas foi analisado usando-se técnicas estatísticas, buscando-se traduzir em números, opiniões e informações para classificá-los e analisá-los. Em seu aspecto qualitativo analisou-se as respostas das questões abertas, que tiveram seus dados tabulados com análise das respostas convergentes entre si.

A população objeto desta pesquisa são os estudantes de um Instituto Federal de Educação, situado no Estado do Rio Grande do Sul, que estão cursando o Curso Técnico a Distância de Nível Médio (educação profissional) no Curso Técnico em Administração que teve seu início em fevereiro de 2012. O curso técnico em administração tem 13 polos EAD, distribuídos pelas cidades do Rio Grande do Sul, atualmente o curso técnico em administração possui 260 estudantes. A técnica para coleta de dados empregada foi a documentação direta, por meio de um questionário 
com perguntas abertas e fechadas aplicado para os 260 estudantes do curso Técnico em Administração em EAD. O questionário foi enviado aos estudantes por meio eletrônico e para estudantes polos via correios para que as tutoras presenciais aplicassem os mesmos de forma presencial.

O questionário utilizado foi adaptado do trabalho "A execução das tarefas virtuais no contexto da educação a distância: um estudo em um curso de graduação em Administração" de Quintana e Quintana (2012).

O questionário original de Quintana e Quintana (2012) era composto por 6 (seis) questões abertas e fechadas, sendo que com as adaptações para este trabalho ficaram 9 (nove) questões entre abertas e fechadas, mais o perfil do estudante, acrescentado neste estudo.

\section{ANÁLISE DOS RESULTADOS}

Para a realização deste estudo foram enviados 260 questionários aos estudantes da Educação Técnica de Nível Médio a distância do curso Técnico em Administração, buscando identificar: os fatores que interferem na decisão da realização de suas tarefas no AVA; quais momentos de estudos ocorrem até a realização das mesmas e qual a percepção que o estudante tem em relação à utilidade da tarefa no processo de avaliação e aprendizagem. Dos 260 questionários enviados obteve-se retorno de 160 questionários válidos.

Do total de 160 questionários, $69 \%$ dos respondentes são do sexo feminino e apenas $31 \%$ são do sexo masculino, sendo que $57,5 \%$ do total são solteiros e $42,5 \%$ do total são casados. Percebe-se que há uma predominância no curso de mulheres solteiras e que sua grande maioria trabalha.

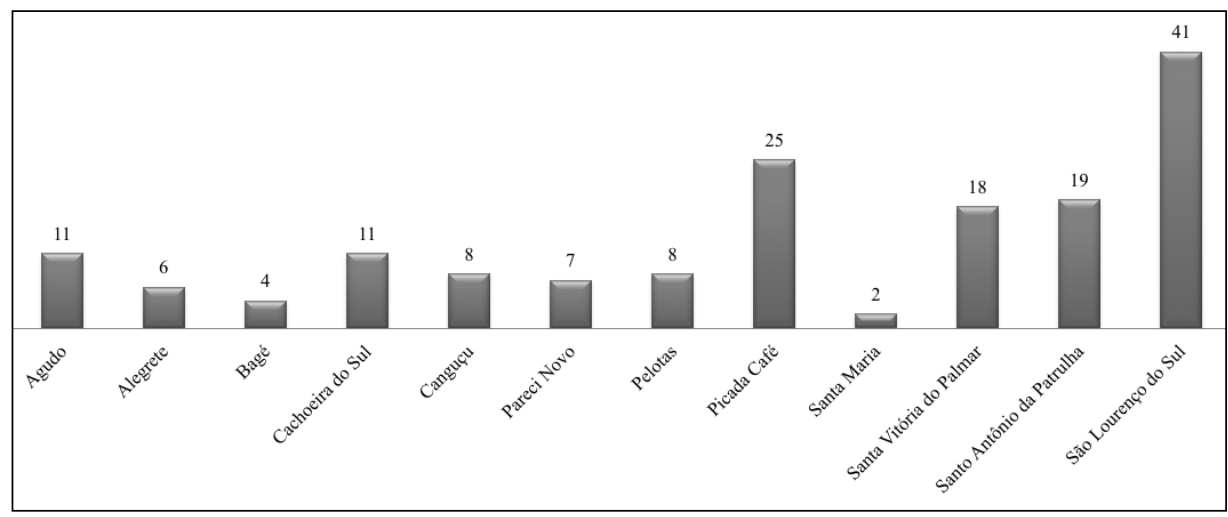

Figura 1. Distribuição dos participantes por pólo Fonte: Dados da pesquisa. 
Quanto à faixa etária da amostra analisada, é possível observar que $72,6 \%$ dos respondentes possuem de 20 a 35 anos, onde: $38,8 \%$ dos estudantes possuem de 20 a 25 anos, e 33,8\% dos estudantes possuem de 26 a 35 anos. Como é possível observar na Tabela 1:

\begin{tabular}{c|c|c}
\hline Faixa Etária & Frequência & Percentual \\
\hline Menos de 20 anos & 8 & $5,0 \%$ \\
$20-25$ anos & 62 & $38,8 \%$ \\
$26-35$ anos & 54 & $33,8 \%$ \\
$36-45$ anos & 30 & $18,8 \%$ \\
$46-50$ anos & 5 & $3,0 \%$ \\
Mais de 50 anos & 1 & $0,6 \%$ \\
\hline
\end{tabular}

Tabela 1. Faixa etária dos participantes da pesquisa Fonte: Dados da pesquisa.

Quando questionados sobre a realização de outros cursos de Ensino a Distância, apenas 29\% dos estudantes já fizeram outro curso a Distância; e 71\% nunca havia feito um curso de Ensino a Distância. Conforme a Tabela 2:

\begin{tabular}{c|c|c}
\hline Respostas & Frequência & Percentual \\
\hline Sim & 46 & $29 \%$ \\
Não & 113 & $71 \%$ \\
\hline
\end{tabular}

Tabela 2. Experiência anterior com o Ensino a Distância. Fonte: Dados da pesquisa.

No que se refere à profissão que possuem, as atividades profissionais mais respondidas foram: comércio, com 32\%; auxiliar administrativo, com 21\%. Além destas a Figura 2 identifica outras profissões:

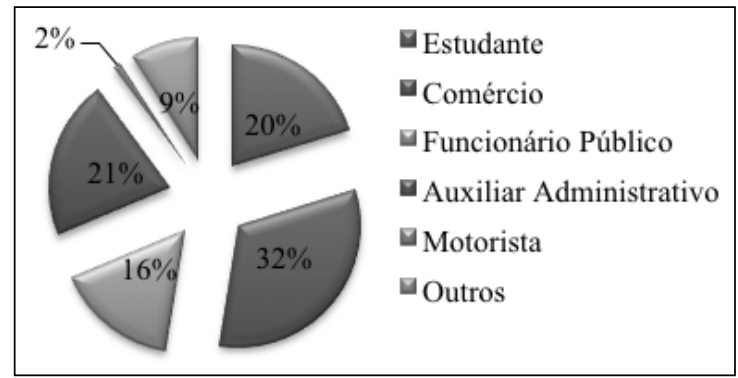

Figura 2. Profissão dos respondentes Fonte: Dados da pesquisa. 
Pelo exposto na Figura 2, a opção por fazer o curso Técnico em Administração pode estar ligada a área de atuação da maioria dos respondentes, alguns estudantes inclusive relatam "que o curso os ajuda muito na sua atividade profissional", "que se utiliza do aprendizado do curso para solução de alguns problemas profissionais"; e "que o curso complementa seus conhecimentos".

Quando abordados sobre quais os fatores que são determinantes na realização das tarefas avaliadas no AVA, o fator que mais se destacou foi o material didático objetivo, sendo elencado por $41 \%$ dos estudantes; o segundo fator mais lembrado foi o tempo disponível para a realização das tarefas, sendo elencado por $22 \%$ dos estudantes; e o terceiro fator mais lembrado foi o comprometimento dos professores nas respostas as dúvidas, sendo elencado por $18,5 \%$ dos estudantes.

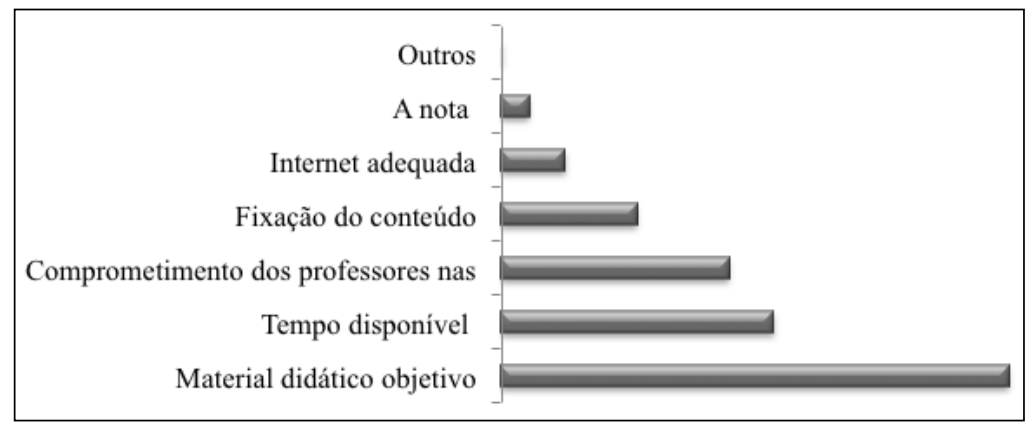

Figura 3. Fatores determinantes na realização das tarefas avaliadas no AVA Fonte: Dados da pesquisa.

O questionamento, abordado na Figura 3, tinha como objetivo verificar o que leva o estudante a fazer sua atividade. Pode-se verificar que o material didático bem elaborado e de fácil compreensão para o estudante é um fator determinante, justificase este fato, pois ao realizar a tarefa não tendo o professor por perto para as devidas orientações, o material didático torna-se sua primeira fonte de pesquisa e de solução de problemas. Santos (2005), em seu trabalho de avaliação no ensino a distância, já alertava da necessidade da $\mathrm{EAD}$ ter uma equipe especializada na preparação, confecção do material, bem como na linguagem a ser utilizada na relação estudante/ professor, que segundo o autor, agora passa a ser mediada pelo material didático. Além do material didático, outro fator, agora de ordem pessoal, é citado pelos estudantes como fator determinante para realização das tarefas, o tempo disponível, pois apesar da educação ser a distância é exigido do estudante tempo para estudo e também para realização de atividades. O fator tempo ter sido elencado por $22 \%$ dos estudantes pode estar relacionado ao fato de $80 \%$ dos estudantes trabalharem, o que pode estar comprometendo o desenvolvimento das atividades. Os estudantes citam 
também como fator determinante na realização das atividades, o comprometimento dos professores em responder as dúvidas referentes ao conteúdo, deixando um alerta para coordenadores de curso a necessidade de ter uma equipe de professores e tutores aptos a responder os questionamentos dos estudantes a qualquer momento.

Quando os estudantes foram questionados sobre quais momentos de estudos ocorrem até a realização das tarefas avaliadas no AVA, três fatores se destacaram: a leitura do conteúdo das apostilas até o total entendimento $32,5 \%$ dos estudantes; o resumo das apostilas e a realização das atividades das mesmas $22,4 \%$; mais uma vez os estudantes se reportam ao material didático como um suporte indispensável para que suas tarefas possam ser concluídas, e estudos diariamente, sendo elencados $10,1 \%$.

Outro questionamento realizado aos estudantes se relaciona à execução da tarefa, perguntando se a execução acontecia no mesmo momento de estudo. A questão tinha 3 opções: "sim", "não" e "as vezes", além de contar com um espaço em branco para observações.

Os estudantes responderam a este questionamento da seguinte forma: $48 \%$ dos estudantes às vezes realiza as tarefas no mesmo momento em que estudou o conteúdo; $42,5 \%$ dos estudantes sempre realiza as tarefas no mesmo momento em que estudou o conteúdo; e apenas $9,5 \%$ dos indivíduos não realiza as tarefas no mesmo momento em que estudou o conteúdo, no espaço aberto para justificativas os estudantes, citam como motivo para não realizar as tarefas no momento de estudo: falta de tempo para conclusão; dificuldade da tarefa; ter de retornar à leitura do conteúdo para melhor entendimento; espera pela resposta do professor e/ou tutor na solução de sua dúvida.

Quando questionados sobre qual melhor dia para realização das tarefas, os finais de semana foram mais lembrados: Sábado, com 61 votos; e Domingo, com 60 votos. Este dado pode estar relacionado ao fato da maioria dos respondentes trabalharem, assim o final de semana acaba sendo utilizado para estudos, 59 estudantes não têm uma preferência por dia.

Quando perguntado aos estudantes qual o melhor dia para ser utilizado como data limite para postagem das tarefas, a maioria dos estudantes entende que os melhores dias para postagem das tarefas são a segunda e a terça-feira. No trabalho de Quintana e Quintana (2012), com estudantes da graduação a maior incidência foi na quarta ou sexta-feira. Acredita-se que esta escolha está vinculada ao fato de $80 \%$, 
conforme dados da Figura 2, dos estudantes trabalharem, assim o fim de semana é utilizado para realização de tarefas, e a segunda e terça-feira para postagem.

Quando questionados sobre qual local era utilizado para realização das tarefas, os estudantes se posicionaram conforme Tabela 3:

\begin{tabular}{c|c|c}
\hline Local & Frequência & Percentual \\
\hline Em casa & 144 & $90,0 \%$ \\
No trabalho & 8 & $5,0 \%$ \\
No polo & 6 & $3,8 \%$ \\
Outros & 2 & $1,2 \%$ \\
\hline
\end{tabular}

Tabela 3, Local de execução das tarefas

Fonte: Dados da pesquisa

Dos 160 estudantes que responderam a pesquisa, $90 \%$ dos respondentes realizam as tarefas em casa, $5 \%$ às realiza no trabalho; $3,8 \%$ realizam as tarefas no polo e $1,2 \%$ em outros locais, como Lan house e hotéis. Percebe-se que apesar da maioria dos estudantes trabalharem, a grande maioria realiza as atividades em casa, o que vem a concorrer com a preferência por realizar as atividades no fim de semana.

Quando questionados sobre o tempo médio utilizado para a realização das tarefas, $48,1 \%$ dos estudantes realizam as tarefas em até uma hora, enquanto que $23,1 \%$ realizam as atividades em até duas horas. Assim, percebe-se que o tempo médio de realização das tarefas é curto, no entanto, como já observado, os períodos de estudos e de esclarecimentos de dúvida acabam tomando mais tempo dos estudantes.

Buscando identificar qual a percepção que o estudante tem em relação à utilidade da tarefa no processo de avaliação e aprendizagem, obtiveram-se os resultados, conforme observa-se na Figura 4:

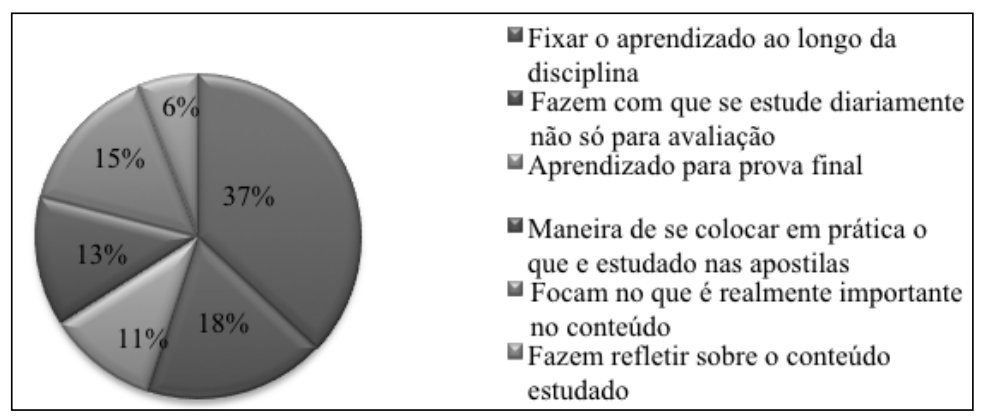

Figura 4. Relevância e utilidade das tarefas no processo de ensino-aprendizagem. Fonte: Dados da pesquisa. 
Desta forma, é possível observar que para os estudantes, a realização das tarefas é de extrema importância para a fixação do conteúdo abordado ao longo da disciplina, tendo esta alternativa a preferência de $37 \%$ dos estudantes; outro fator bastante relevante foi a importância das tarefas para estimular os estudantes ao estudo diário, e não apenas para obtenção de notas. Assim como no trabalho de Quintana e Quintana (2012), com estudantes de graduação, os estudantes da educação técnica de nível médio, também julgam as tarefas como de suma importância para fixação do conteúdo, de estudo diário, bem como um aprendizado para prova final.

Analisando as respostas de cada pólo, nota-se no polo São Lourenço do Sul, que 29 estudantes são do sexo feminino e a maioria está na faixa etária de 20 a 35 anos. Para este grupo, as tarefas são destacadas como facilitadoras no processo ensino-aprendizagem, além de prepararem para a avaliação, outro destaque é que as mesmas são usadas no dia a dia profissional de alguns estudantes. Neste grupo há alguns relatos que devem ser observados, para que as tarefas cumpram com sua função: "é muito difícil e preciso muito estudo e comprometimento e também maior apoio dos professores e tutores"; "O conteúdo às vezes é bastante difícil e os chats de dúvidas poderiam ser em horários noturnos em que todos ou a maioria podem acessar o ambiente e também com assuntos específicos do conteúdo, pois muitas vezes há assuntos paralelos"; "material um pouco mais explicativo para melhor entendimento do conteúdo"; "as atividades são extensas e muitas vezes temos só uma semana para postagem”. Já os estudantes do sexo masculino do polo São Lourenço do Sul, estão em sua grande maioria na faixa etária de 20 a 25 anos, também justificam que as tarefas são de extrema importância no processo ensinoaprendizagem e que muitas vezes são usadas no seu trabalho.

No polo de Picada Café, dos 25 estudantes respondentes da pesquisa, 20 são do sexo feminino estando na faixa etária de 20 a 35 anos, sendo apenas 5 do sexo masculino estando estes na faixa etária de 20 a 25 anos. A maioria dos estudantes relata as tarefas como sendo muito importantes para entender a disciplina e fundamentais para o aprendizado. Neste polo também há relatos que pedem a atenção dos educadores em EAD, são eles: "por serem tarefas da modalidade EAD e por terem limite de tempo deveriam ser mais claras e objetivas"; o que vem a justificar a resposta dada a questão "quais fatores são determinantes na realização de suas tarefas avaliadas no AVA?", dos 160 respondentes, 127 responderam como fator determinante material didático objetivo; "questões mais dissertativas, para que possa haver maior interação entre estudantes e professores". Bassani e Behar (2006), em sua análise para interações em ambientes virtuais de aprendizagem já alertavam para que a tarefas não se resumissem a uma série de questões corrigidas 
pelo sistema, mas que também envolvessem a produção individual do estudante com pesquisas, textos e fóruns para troca de experiências e uma maior interação entre os estudantes.

Em Santo Antônio da Patrulha, dos 19 respondentes da pesquisa, 10 são do sexo masculino, na faixa etária de 20 a 45 anos e 9 são do sexo feminino estando na faixa etária de 20 a 35 anos, entre estes estudantes as tarefas são destacadas como um reflexo do que vai ser solicitado na avaliação, além de fazer com que o estudante crie o hábito de estudar diariamente não só para avaliação final, há também solicitações para que sejam disponibilizados mais vídeos sobre as disciplinas e web conferência.

No polo de Santa Vitória do Palmar tem-se um total de 18 estudantes respondentes da pesquisa, sendo 10 do sexo feminino estando na faixa etária dos 20 a 35 anos e 8 do sexo masculino, faixa etária de menos 20 a 35 anos. De forma geral, avaliam as tarefas como essenciais para fixação do conteúdo. Também creditam que as mesmas têm uma forma de interação entre os estudantes, bem como uma forma de trocar informações. Babin e Kouloumdjian (1989), em suas pesquisas com jovens ante a realidade advinda com os avanços tecnológicos, já relatavam que estas alternativas de aprendizagem auxiliam os estudantes a interagir e a participar das estruturas sociais e educativas.

Por fim, buscou-se identificar a percepção dos estudantes sobre o reflexo das tarefas avaliadas na sua avaliação final, obtendo-se os seguintes resultados:

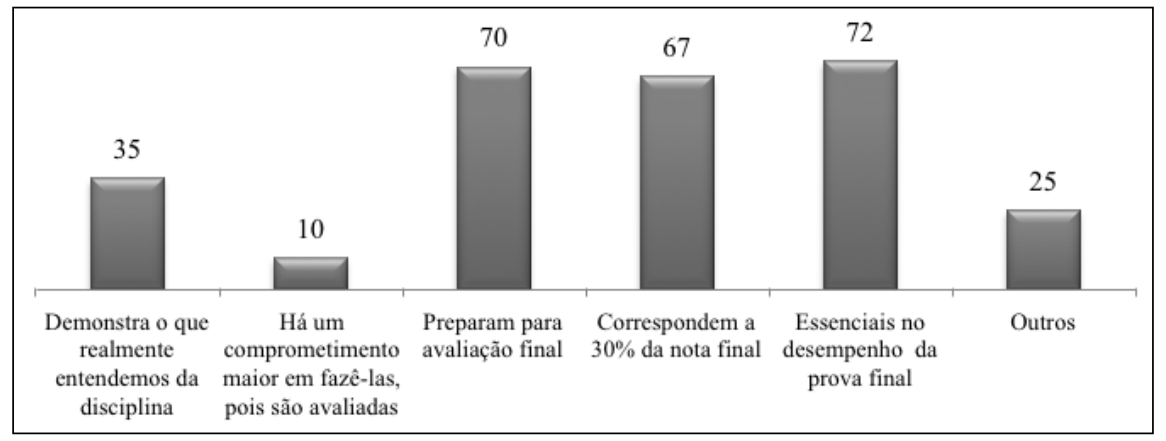

Figura 5. Percepção dos estudantes sobre o reflexo das tarefas na sua avaliação final Fonte: Dados da pesquisa.

De uma forma geral, identifica-se que para os estudantes as tarefas primeiramente são de extrema importância para melhorar o desempenho na prova final, além de servir como preparação para a mesma. 
No polo de São Lourenço do Sul há um consenso entre os estudantes de que as tarefas têm um reflexo extremamente positivo na avaliação final. Seguem alguns relatos: "demonstra o que realmente aprendemos"; "muito importante, pois nos auxiliam nos estudos e nas notas"; "essencial para aprendizagem"; "fixa a matéria e já me prepara para avaliação"; "são essenciais, pois ajudam bastante no desempenho da prova"; "as tarefas contribuem para fixar o conteúdo além de contribuir com a nota final”.

Em Picada Café os relatos destacam também a importância das tarefas na avaliação final. Os relatos são: "As avaliações vão refletir na minha nota final, se nas avaliações eu obter uma média alta significa que estou preparado para avaliação final"; "serve para avaliar o conhecimento adquirido e isso na maioria das vezes depende do interesse do estudante"; "as tarefas que realizamos servem para fixarmos o conteúdo, aprendermos de fato o que lemos, e também como um treino para a avaliação final"; "uma maior aptidão para a realização das provas e maior conhecimento"; "fundamentais, pois a avaliação está baseada nas atividades avaliativas, são treinamentos antes da avaliação final, na qual podemos nos basear para a essência da disciplina, reforçando assim o aprendizado"; "as tarefas avaliadas nos posicionam do quanto da matéria foi captada e entendida”.

Os 19 respondentes do polo Santo Antônio da Patrulha também consideram que as tarefas avaliadas no ambiente virtual refletem positivamente em sua nota final, os relatos são: "são muito importante, pois nos auxilia nas notas, não sendo apenas as notas das provas a valer, também nos mostra os pontos importantes da matéria, os exercícios nos ajudam a estudar"; "apontam o que o estudante aprendeu durante a disciplina, o que pode ser mudado e o que está dando bom resultado"; "muito importante, além de somar com a nota da prova, serve para o preparo da prova"; "é a maneira que temos de mostrar nosso aprendizado"; "são muito importante, pois a nota obtida através das tarefas avaliadas permite maior tranquilidade no momento da avaliação final"; "são importantes para compor a nota e uma forma de preparação para a avaliação final”.

Em Santa Vitória do Palmar é consenso entre os 18 estudantes, que participaram da pesquisa, que a tarefas avaliadas refletem em sua nota de forma positiva e que os preparam para avaliação final, os relatos são: "Auxiliam na compreensão do conteúdo, contribuindo para uma boa avaliação"; "refletem de forma extremamente positiva, além de preparar para a avaliação final"; "medem minha responsabilidade e comprometimento com o curso, além de refletir meu conhecimento sobre o conteúdo"; "as tarefas me auxiliam no estudo, pois me mostram se tenho um bom entendimento da disciplina estudada, se me saio bem nas atividades, me sinto preparada para a 
avaliação final”; "com as tarefas eu sempre entendo melhor o conteúdo, pois nelas sempre são questionados os pontos mais importantes da disciplina”.

Os demais estudantes relatam o mesmo entendimento, de que as atividades avaliadas no ambiente virtual de aprendizagem refletem positivamente em sua avaliação final, além de servir como um meio de estudo para a mesma.

Pelos relatos destacados neste trabalho, percebe-se que os estudantes consideram as tarefas avaliadas no ambiente virtual de aprendizagem essenciais no seu processo ensino-aprendizagem, além de destacarem que as mesmas são necessárias para um bom rendimento na sua avaliação final.

\section{CONSIDERAÇÕES FINAIS}

O presente trabalho teve por objetivo analisar a percepção dos estudantes da educação técnica a distância de nível médio sobre a realização de suas tarefas avaliadas no ambiente virtual de aprendizagem. Para atender o objetivo buscouse verificar quais fatores interferem na decisão de resolução das tarefas virtuais. Teve-se como resultado que a resolução das tarefas sofre algumas influências como a necessidade de um material didático objetivo e de fácil entendimento para o estudante; o tempo disponível para realização das mesmas; bem como o comprometimento de professores e tutores com as dúvidas. Percebe-se também que as tarefas normalmente são realizadas em casa, não sendo desenvolvidas no mesmo momento destinado para estudo, que os dias preferidos para execução das mesmas são o final de semana e que para postagem final é a segunda e a terça-feira.

Atendendo responder um dos objetivos específicos, procurou-se identificar quais momentos de estudos ocorrem até a finalização da tarefa. Neste sentido, percebeu-se que os estudantes levam um tempo médio de 1 a 2 horas, tempo relativamente curto, mas se verifica pelos relatos, que os estudantes estudam até o total entendimento do conteúdo da apostila, além de muitos ainda elaborarem resumos das mesmas para estudo, o que conclui-se que quando o estudante parte para fazer as atividades, já tem um certo domínio do conteúdo.

Outro objetivo específico a ser respondido diz respeito a importância das tarefas avaliadas no seu processo de aprendizagem. A maioria dos estudantes acredita que as mesmas servem para fixação do aprendizado ao longo da disciplina, além de ser uma forma de fazer o estudante estudar diariamente, não deixando assim os estudos só para hora da avaliação. Quanto ao reflexo destas atividades na sua avaliação final, os estudantes consideram como essenciais no desempenho da avaliação final assim 
como uma preparação para a mesma. Sendo assim percebe-se que os estudantes veem as tarefas avaliadas como um subsídio de extrema importância em todo o processo ensino-aprendizagem em EAD.

Neste trabalho procurou-se verificar o entendimento dos estudantes em relação à utilidade das atividades avaliadas no processo ensino aprendizagem em EAD, contudo seria importante outros estudos e comparações.

Por fim, o resultado deste trabalho evidencia alguns cuidados que devem ter coordenadores e professores em EAD, como material didático, com a questão do tempo disponibilizado para realização das tarefas e postagem e com o retorno nas questões em que envolvem as dúvidas dos estudantes; estes solicitam um maior comprometimento por parte de professores e tutores nas respostas as suas dúvidas. Acredita-se que com uma maior atenção a estas solicitações, as tarefas avaliadas terão cada vez mais relevância e importância neste processo ensino-aprendizagem.

\section{REFERÊNCIAS BIBLIOGRÁFICAS}

Alonso, K. (2005). A avaliação e a avaliação na Educação a Distância. In: Preti, O. (Org.). Educação a Distância: sobre discursos e práticas (91-106). Brasília: Liberlivro.

Aretio, L. G. (1995). Educación a distancia hoy. Madrid: UNED.

Babin, P.; Kouloumdjian, M. F. (1989). Os novos modos de compreender: a geração do audiovisual e do computador. São Paulo: Paulinas.

Barbosa, D. N. F.; Batista, M. M.; Orth, M. A.; Sarmento, D. F.; Castro, V.; Cortez, E.; Ramires, V. L. (2007). Educação a distância no ensino superior: caminhos organizacionais percorridos e suas propostas de formação de professores. Colabor@ - Revista Digital da CVA - Ricesu, 4 (16), (1-20). [em línea] Disponível em: http://www.ricesu.com. $\mathrm{br} /$ colabora/n16/artigos/n 16/pdf/ id 01.pdf (consulta 2012, 12 de julho).

Barilli, E. C. V. C. (2006). Avaliação: acima de tudo uma questão de opção. In: Silva, M.; Santos, E. (Orgs.). Avaliação da
Aprendizagem em Educação On line (153-170). São Paulo: Loyola.

Barreto, A. de A. (1996). Eficiência técnica e econômica e a viabilidade de produtos e serviços de informação. Ciência da Informação, 25 (3), (2-18). [em línea] Disponível em: http://revista.ibict.br/ cienciadainformacao/index.php/ciinf/ article/view/466 (consulta 2012, 12 de julho).

Bassani, P. B. S.; Behar, P. A. (2006). Análise das interações em ambientes virtuais de aprendizagem: uma possibilidade para avaliação da aprendizagem em EAD. Revista Novas Tecnologias na Educação - RENOTE, 4 (1), (1-10). [em línea] Disponível em: http://seer.ufrgs. br/renote/article/viewFile/14044/7932 (consulta 2012, 12 de julho).

Brasil. (2005). Decreto n. 5.622, de 19 de dezembro de 2005. (2005, 23 de dezembro). Regulamenta o art. 80 da Lei $\mathrm{n}^{0}$ 9.394, de 20 de dezembro de 1996, que estabelece as diretrizes e bases da educação nacional. Diário Oficial $d a$ União, seção 1. [em línea] Disponível em: 
http://www.planalto.gov.br/ccivil 03/ Ato2004-2006/2005/Decreto/D5622. htm (consulta 2012, 12 de julho).

Brasil. (1996). Lei n. 9.394, de 20 de dezembro de 1996. (1996, 23 de dezembro). Estabelece as Diretrizes e Bases da Educação Nacional. Diário Oficial da União, seção 1. [em línea] Disponível em: http://www.planalto.gov.br/ccivil 03/ leis/l9394.htm (consulta 2012, 16 de julho).

Coordenação de Aperfeiçoamento do Pessoal de Nível Superior - CAPES-UAB. (2012). Histórico. [em línea] Disponível em: http://uab.capes.gov.br/index. php?option $=$ com content\&view $=$ article \&id=9\&Itemid=21 (consulta 2012, $12 \mathrm{de}$ julho).

Fuks, H.; Gerosa, M. A.; Lucena, C. J. P. (2001). Sobre o Desenvolvimento e Aplicação de Cursos Totalmente a Distância na Internet. Revista Brasileira de Informática na Educação, 9 (9), (6175). [em línea] Disponível em: http:// groupware.les.inf.puc-rio.br/public/ papers/TIAESBC-IE.pdf (consulta 2012, 14 de julho).

Gil, A. C. (2010). Como elaborar projetos de pesquisa, 5 a ed. São Paulo: Atlas.

Haydt, R. C. (2002). Avaliação do processo ensino-aprendizagem. São Paulo: Ática.

Keegan, D. (1991). Foundations of distance education, 2a ed. Londres: Routledge.

Kenski, V. M. (2003). Tecnologias e ensino presencial e a distância. Campinas: Papirus.

Libâneo, J. C. (1991). Didática. São Paulo: Cortez.

Luckesi, C. C. (2005). Avaliação da aprendizagem na escola: reelaborando conceitos e recriando a prática. Salvador: Malabares Comunicação e Eventos.

Maciel, I. M. (2002). Educação a distância e ambiente virtual: construindo significados. Boletim Técnico do SENAC, 28 (3), (38-45).
Maia, C.; Mattar, J. (2007). ABC da EAD: a educação a distância hoje. São Paulo: Pearson Prentice Hall.

Ministério da Educação do Brasil. (2012). Rede e-TEC Brasil. [em línea] Disponível em: http://portal.mec. gov.br/index.php?option =com content\&view $=$ article\&id $=12326: e$-tecapresentacao\&catid=293: escola-tecnicaaberta-do-brasil-e-tec\&Itemid $=665$ (consulta 2012, 12 de julho).

Miranda, G. L. (2007). Limites e possibilidades das TIC na educação. Revista de Ciências da Educação, 3 (3), (41-50). [em línea] Disponível em: http://sisifo.fpce.ul.pt/?r=11\&id $=74$ (consulta 2012, 12 de julho).

Moodle (2012). Open Source de Gerenciamento de Cursos. [em línea] Disponível em: https://moodle.org/ about/ (consulta 2012, 12 de julho).

Moran, J. M. (2011). O que é Educação a Distância [em línea] Disponível em: http://www.eca.usp.br/prof/moran/ dist.htm (consulta 2012, 12 de julho).

Moura, A. M. M.; Azevedo, A. M. P.; Mehlecke, Q. (2011). As Teorias de Aprendizagem e os Recursos da Internet Auxiliando o Professor na Construção do Conhecimento. Publicação on line da Associação Brasileira de Educação a Distância. [em línea] Disponível em: $\quad$ http://www2.abed.org.br/ visualizaDocumento.asp?.Documento ID $=17$ (consulta 2012, 12 de julho).

Otsuka, J. L.; Rocha, H. V. (2012). Avaliação Formativa em Ambientes de EAD. In: 13 Simpósio Brasileiro de Informática na Educação, São Leopoldo: SBIE. [em línea] Disponível em: Recuperado em: http://www.teleduc.org.br/artigos/17 ih sbie2002.pdf (consulta 2012, 12 de julho).

Piletti, C. (1987). Didática geral. São Paulo: Ática.

Porfirio, J. H.; Mello, L. S. (2007). Aprender a distância e ensinar: o uso do 
recurso midiático (computador) como instrumento educacional em cenário de formação docente. 16 Congresso de Leitura do Brasil. Campinas: Associação de Leitura do Brasil. CD-ROM.

Quintana, A. C.; Quintana, C. G. (2012). A execução das tarefas virtuais no contexto da educação a distância: um estudo em um curso de graduação em administração. Revista Gestão Universitária na América Latina - GUAL, 5 (2), (277-297). [em línea] Disponível em: http://www. periodicos.ufsc.br/index.php/gual/ article/view/1983-4535.2012v5n2p277 (consulta 2013, 05 de agosto).
Santos, J. F. S. (2005). Avaliação no ensino a distância. Revista Ibero-americana de Educação, 38 (4). [em línea] Disponível em: http://www.rieoei.org/ deloslectores/1372Severo.pdf (consulta 2012, 27 de outobro).

Silva, M. (2006). O Fundamento Comunicacional da Avaliação da Aprendizagem na Sala de Aula On line. In: Silva, M.; Santos, E (Orgs.). Avaliação da Aprendizagem em Educação On line. São Paulo: Loyola.

Zabala, A. (1999). Como trabalhar os conteúdos procedimentais em aula, 2a ed. Porto Alegre: Artmed.

\section{PERFIL ACADÊMICO E PROFISSIONAL DOS AUTORES}

Alexandre Costa Quintana. Doutorando em Controladoria e Contabilidade pela Universidade de São Paulo (USP), Mestre em Administração pela Universidade FederaldeSantaCatarina(UFSC)eGraduadoem Ciências ContábeispelaUniversidade Federal do Rio Grande (FURG). Atualmente é professor da Universidade Federal do Rio Grande (FURG). Tem experiência na área de Contabilidade, com ênfase em Contabilidade Geral e Pública, atuando principalmente nos seguintes temas: contabilidade pública, transparência, tecnologias da informação e comunicação na educação e pesquisa em contabilidade.

E-mail: professorquintana@hotmail.com

Vera Lucia Pinheiro Fernandes. Graduação em Ciências Contábeis pela UCPEL e Especialização em Ciências Contábeis pela FURG. Atua como professora de Nível Técnico Profissional pelo Estado do RGS, também como professora Conteudista dos Cursos Técnicos de Nível Médio em EAD do Campus Visconde da Graça.

E-mail: veralpfernandes@gmail.com

DIRECCIÓN POSTAL DE LOS AUTORES

Rua Chefe Carlos Araujo, 166

Rio Grande, RS - Brasil.

Fecha de recepción del artículo: 08/11/13

Fecha de aceptación del artículo: 13/02/14 


\section{Como citar este artículo:}

Costa Quintana, A.; Pinheiro Fernandes, V. L. (2014). Percepção do Estudante de Educação Técnica a Distância de Nível Médio sobre a realização das Tarefas Avaliadas no Ambiente Virtual. RIED. Revista Iberoamericana de Educación a Distancia, volumen 17, $\mathrm{n}^{\mathrm{O}}$ 2, pp. 127-150. 